\title{
Assessment of Potential Ecotourism Site in Xaisomboun, Central Laos
}

\section{Soneteng Buaxaiya ${ }^{1 *}$, Chittana Phompila1, Kaisone Phengsopha2 ${ }^{2}$, Bakham Chanthavong3, Kethsa Nanthavongduangsy ${ }^{4}$, Sithong Thongmanivong1, Himlal Baral ${ }^{5}$}

${ }^{1}$ Faculty of Forest Sciences, The National University of Laos, Vientiane Capital, Lao People's Democratic Republic ${ }^{2}$ Postgraduate Office, The National University of Laos, Vientiane Capital, Lao People's Democratic Republic ${ }^{3}$ Vietnam National University of Forestry (VNUF), Xuan Mai, Chuong My, Hanoi, Viet Nam

${ }^{4}$ Kunming University Science and Technology, Kunming, China

${ }^{5}$ Center for International Forestry Research (CIFOR), Situ Gede, Sindang Barang, Bogor, Indonesia

Email: ^buaxaiyas@gmail.com

How to cite this paper: Buaxaiya, S., Phompila, C., Phengsopha, K., Chanthavong, B., Nanthavongduangsy, K., Thongmanivong, S., \& Baral, H. (2021). Assessment of Potential Ecotourism Site in Xaisomboun, Central Laos. Journal of Service Science and Management, 14, 680-695.

https://doi.org/10.4236/jssm.2021.146043

Received: November 21, 2021

Accepted: December 27, 2021

Published: December 30, 2021

Copyright $\odot 2021$ by author(s) and Scientific Research Publishing Inc. This work is licensed under the Creative Commons Attribution International License (CC BY 4.0).

http://creativecommons.org/licenses/by/4.0/ (c) (i) Open Access

\begin{abstract}
Appropriate ecotourism planning is crucial for sustainable ecotourism development in developing countries including Laos. The primary objective of this research was to identify the potential sites for ecotourism in order to assist in planning and decision making to ensure the sustainable natural forest resource management. GIS data analysis was undertaken to assess the potential sites for ecotourism. We used seven factors describing biophysical characteristics; forest cover, water, elevation, slope, proximity to village, road accessibility and historical attractive sites. It was found that there is around 1200 ha of the entire area of Xaisomboun province which is the most suitable for inland recreational activities, about 1980 ha for beautiful ecological sceneries, roughly 1143 ha for historical tourism activity sites, and finally 1031 ha of a total area that most suitable for multipurpose ecotourism activities. These most suitable areas are located mostly in the protected areas, dense forests and high value of natural resources. These are also major attractions for historical and country revolutions. There is a need to incorporate appropriate infrastructures and local engagement and services. The result is useful for ecotourism development and great benefit in terms of sustainable social-economic development, conservation of biodiversity and other ecosystem services.
\end{abstract}

\section{Keywords}

Ecotourism, Site Assessment, Weight Overlay, Land Suitability, Xaisomboun, Laos 


\section{Introduction}

Laos is one of the richest biodiversity countries in the Southeast Asia. Its natural landscapes consist of spectacular limestone mountains, rainforests and large waterfalls, as well as unique local ethnic cultural and historical features (Phompila, Lewis, Ostendorf, \& Clarke, 2017; Yongnou et al., 2019). These can offer a great opportunity for ecotourism development. The dense forests and attractive landscape are natural habitats for significant biodiversity including endangered plants and wild animals (Fujita \& Phanvilay, 2008). About 50 percent of the country's land area consists of 23 national and provincial biodiversity conservation areas (NBCAs) (Kim \& Alounsavath, 2015). According to the Lao Statistics Bureau, there are almost nine hundred thousands of local ethnic people living in over 1200 villages within these NBCAs. Most of these people have relied heavily on existing natural resources for their nutrition and livelihoods. As a result, the natural forest resources have been under pressure and declining rapidly (Meyfroidt, Lambin, Erb, \& Hertel, 2013; Phompila et al., 2017). Ecotourism is expected to be one of alternative solutions to sustain the nation's natural forest resources and improve local livelihoods. It is expected to generate national revenue and create green jobs and livelihood opportunities for local communities, aligning with green economic growth. In 2009, there were about 2 million tourists in Laos, which contributed about 270 million US dollars totally to its national revenue (Schipani, 2011; Yamano et al., 2020). This figure was predicted to potentially increase in the coming years.

The key concept of the ecotourism development refers to the need of making a balance between environmental and economic aspects of protecting natural and ecological resources sustainably, while gaining social-economic development (Diamantis, 1999; Dimitriou, 2017; Simonekeo, 2015). However, if not planned and managed appropriately, it could lead a massive destruction of nature. There is a need to have accurate development and planning of ecotourism on the lands, in particular for local authorizes in Laos with limited technical capacities. Suitable site assessment is required to provide a guide on the land use and infrastructure decisions for ecotourism. This is a necessary for preserving the natural, cultural, and historical values of the suitable sites. Geographic information systems (GIS) analysis is commonly used for the efficiency and quality of spatial data assessment for suitable ecotourism site selection. Several studies have been applied successfully worldwide (Taye et al., 2019; Çetinkaya, Kabak, Erbaş, \& Özceylan, 2018; Nisa, 2017; Omarzadeh et al., 2021; Waswa Wanyonyi, Imwati, \& Boitt, 2016).

As well understood, the ecotourism is one of the most attractive subsets of tourism industry which can contribute to natural resource preservation and livelihood development under proper management. The most stable solution in developing countries for developing ecotourism is through proper assessment, identification and prioritization of different areas with the capacity to support tourism within the counties and country at large, and then creating enabling en- 
vironment through infrastructure creation. This is seriously missed in the ecotourism development at local and national development planning processes in Laos. This criteria and indicators GIS approach can be adopted to ensure the sustainable ecotourism development and planning.

The overall goal is to identify the potential sites for ecotourism in order to assist in the decision making of the concerned authorities to sustain the natural forest resources and environment of these attractions. We analyzed areas that can be promoted for inland recreational activities, beautiful ecological sceneries, historical tourism activity sites, as well as for multipurpose ecotourism development activities

Appropriate ecotourism planning is needed for sustainable ecotourism development in Laos especially by suggesting appropriate decision options on landscapes. This is the greatest benefit in terms of sustainable social-economic development, conservation of biodiversity and other ecosystem services. Thus, we focused on GIS applications for modelling and mapping of ecotourism. We selected a comprehensive set of seven factors describing biophysical characteristics to develop a model for choosing potential ecotourism sites. The resulting information can be useful for ecotourism development and planning, however a challenge for a decision maker is how to manage ecotourism in order to minimize the negative impacts.

\section{Materials and Methods}

\subsection{Study Area}

In this study, we focus on Xaisomboun province, a central of Laos (Figure 1). It is one of the newly established provinces in the center of the country, connecting four provinces from the North to the South. This region is rich in natural forest resources and biodiversity which can be attractive tourist destinations. This province is about 8300 square kilometers (3204.64 sq.miles). Elevation range from about 200 to 2820 meters (the highest mountain is called Phou Bia). Due to its ruggedness, the province lacks significant human settlement.

Xaisomboun province has 599,570 hectares of forest areas, accounting for $73.74 \%$ of total land, including 32,260 hectares of provincial protected areas, 437,790 hectares of national protected forests and 129,520 hectares of other forests (Department of Forestry, 2018). It has a variety of forest cover types; mainly evergreen forests, deciduous forests, mixed forests, pine forests, wetlands and some croplands. Forests are largely distributed across the province, which are mostly mountainous. These areas are also hotspots of mining and prioritized development targets of the government.

This rugged and largely inaccessible area due to unique terrains which consists of important stream-rivers and reservoirs. It is a significant tributary of the Mekong. The Nam Ngum Dam, Laos's largest hydroelectric project, impounds the Nam Ngum south of the province. This large reservoir is also a natural habitat to a wide variety of plant and aquatic species. There are also many streams 


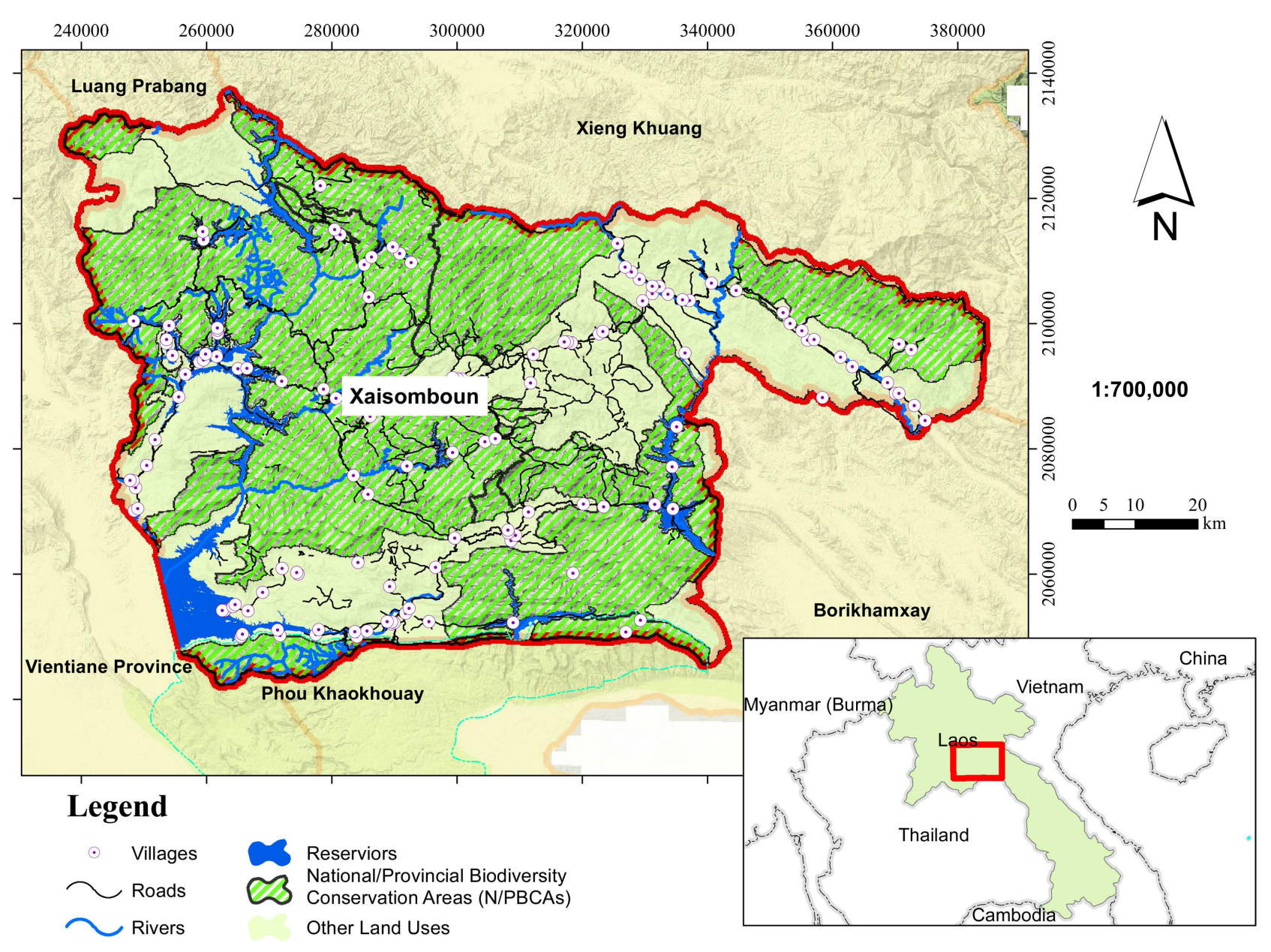

Figure 1. The case study area's geographical location (Xaisomboun province, a central of Laos). Source: all spatial data was collected from PoNRE in Xaisomboun province.

such as Nam Ngep, Nam Chieng, Nam Sank, Nam Pha, Nam Yam, Nam Pheuk, Nam Chang, Nam Che, Nam Thanh, Nam Xan and Nam Mang.

There are key corridor road networks of the province which are useful interconnected to other parts of the country such as Anouvong Road to Road No.1D, and Nam Yone Road to Road No.13 South. Four surrounded provinces have crucial benefits from this connection such as Vientiane, Luang Prabang, Xiengkhuang and Bolikhamxay. This provides a foundation for an integration of the ecotourism among the Laos and Greater Mekong Sub-region.

Cultural tradition is very attractive for cultural tourism development besides ecologically sustainable ecotourism development which can be adopted in the future.

\subsection{Methods}

In this research, we applied the common weighted overlaying method in GIS environment. Research methodology is shown in flow chart (Figure 2). This has been used for evaluation of ecotourism site suitability evaluation in several studies (Taye et al., 2019; Çetinkaya et al., 2018; Ahmadi et al., 2015; Nisa, 


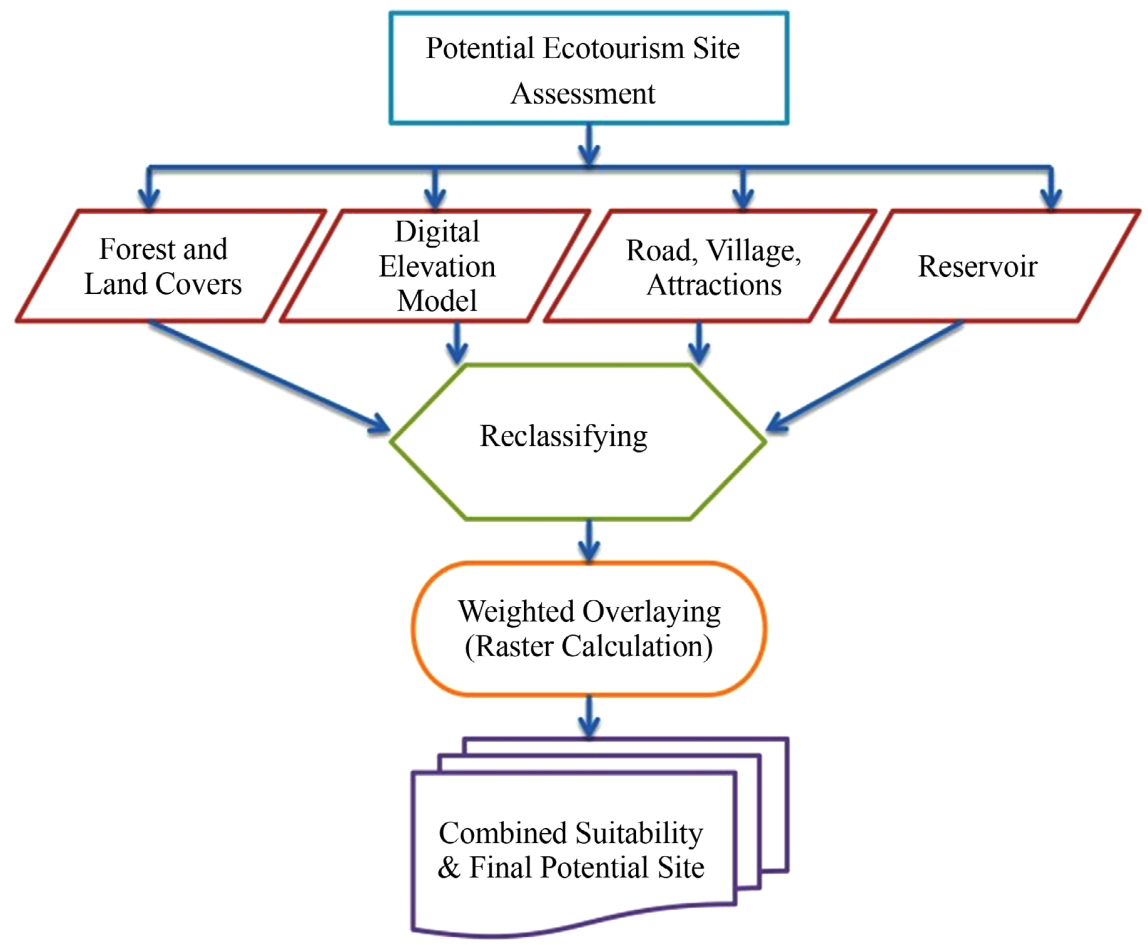

Figure 2. Research methodology flow chart.

2017; Omarzadeh et al., 2021; Waswa Wanyonyi et al., 2016). Biophysical land features were used to identify potential ecotourism sites within the study area, including seven key features forest cover, reservoir, elevation, slope, road access, village locations, and attractive tourism locations such as historical and cultural sites, unique plants and wildlife (Table 1 and Figure 3). These existing spatial data was prepared and analyzed by in Opened Sources GIS Software (QGIS). Other specific biophysical features were not included due to limited data reliability from the local government such as climate/weather, etc. Thus, this study is claimed to be the first study for potential ecotourism assessment of Xaisomboun province.

\subsubsection{Data Used and Sources}

Data used in this study was primary from the Lao government sectors (Figure 3, Table 1 and Table 2). Firstly, the spatial data was mainly collected from the provincial natural resource and environment (PoNRE), in Xaisomboun province, including forest cover and land use (extracting only provincial and national protected areas), reservoir areas, tourism attractive locations, road networks (permanent and temporally or unpaved roads), and village locations. In addition, USGS data was obtained such as digital elevation model (DEM) to produce elevation and slope data for the study area.

All available spatial data was prepared based on the 4 standard criteria; highly suitable, moderately suitable, marginally suitable and not suitable (using ranking 1 - 4 respectively). The GIS-based land suitability analysis has been applied for provincial administrative boundary. 
Table 1. A list of data and their original sources.

\begin{tabular}{ccc}
\hline Description & Data Types/Format & Sources \\
\hline $\begin{array}{c}\text { Forest Cover and Land Use } \\
\text { (Protected Areas) }\end{array}$ & Polygons in 2015 & PoNRE, Laos \\
Reservoir & Polygons in 2015 & PoNRE, Laos \\
Tourism Attractive Locations & Data Points in 2015 & PoNRE, Laos \\
Roads & Lines in 2015 & PoNRE, Laos \\
Elevation & Raster 30 m resolution & USGS \\
Slope & Raster 30 m resolution & USGS \\
Villages & Data Points in 2015 & NSC, Laos \\
Forest Cover and Land Use & Polygons in 2015 & PoNRE, Laos \\
\hline
\end{tabular}

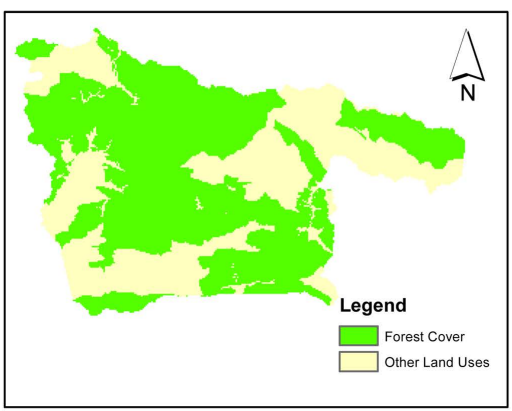

(a)

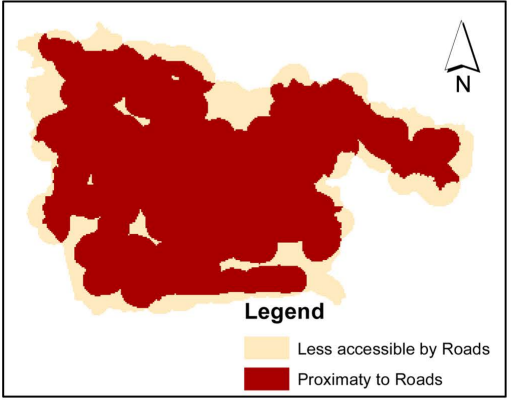

(d)

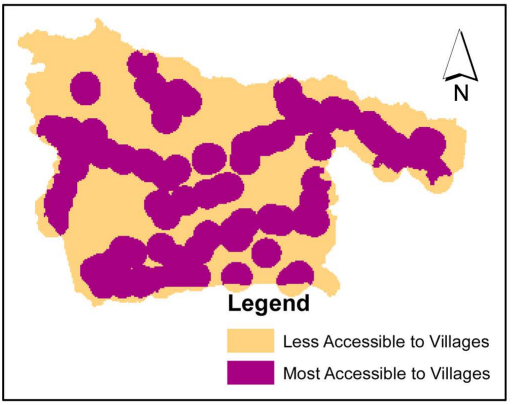

(g)

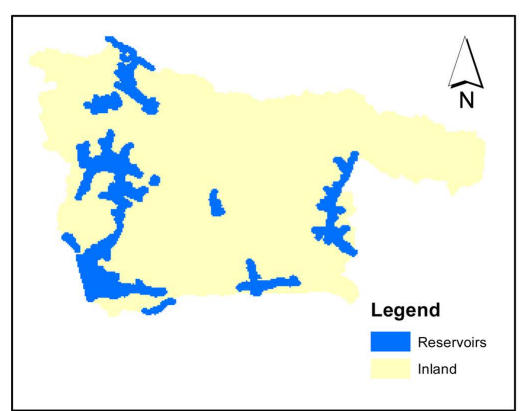

(b)

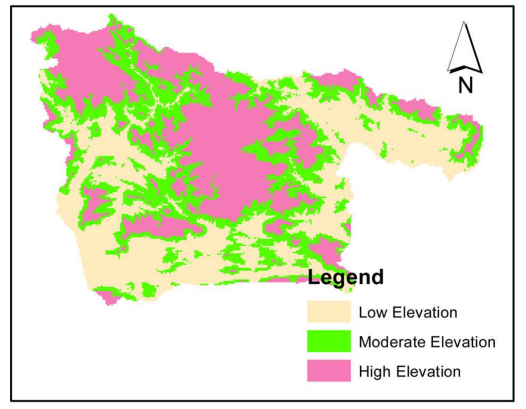

(e)

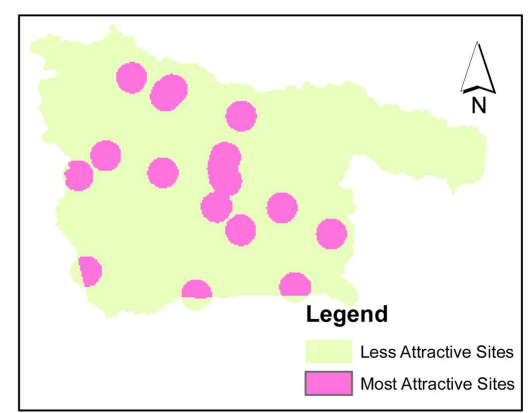

(c)

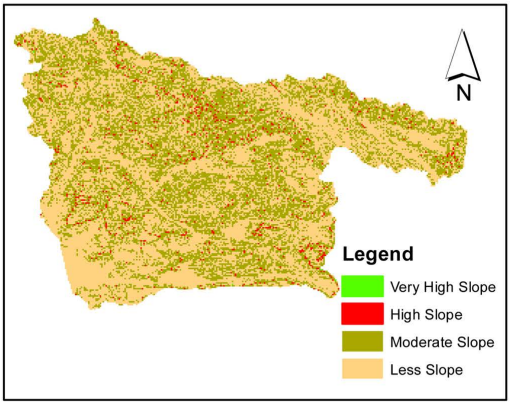

(f)

Figure 3. Prepared data and used for GIS analysis-(a) forest cover, (b) reservoir, (c) historical sites, (d) roads, (e) elevation, (f) slope, and (g) village locations. Source: all spatial data was collected from PoNRE in Xaisomboun province. 
Table 2. Applied criteria for overlaying of the map layers.

\begin{tabular}{|c|c|c|}
\hline No & Map Layers & Set Criteria \\
\hline 1 & $\begin{array}{l}\text { Forest Cover and Land Use } \\
\text { (Protected Areas) }\end{array}$ & $\begin{array}{l}\text { Dense forest covers in National/Provincial } \\
\text { Biodiversity Conservation Areas are suitable } \\
\text { for beautiful ecotourism sceneries }\end{array}$ \\
\hline 2 & Reservoir & $\begin{array}{l}\text { Areas within } 1-\mathrm{km} \text { around the reservoir, } \\
\text { lake and aquatic surfaces such as hydropower } \\
\text { and rivers are suitable for inland recreational } \\
\text { activities such as water sports, fishing and } \\
\text { camping }\end{array}$ \\
\hline 3 & Tourism Attractive Locations & $\begin{array}{l}\text { Areas situated at a distance of } 5-\mathrm{km} \text { away } \\
\text { from tourism attractive points are suitable } \\
\text { sites such as the historic monuments, } \\
\text { cave and interesting features }\end{array}$ \\
\hline 4 & Roads & $\begin{array}{l}\text { Proximately distance of } 5-\mathrm{km} \text { away from } \\
\text { roads are considered to be easy accessible to } \\
\text { ecotourism sites }\end{array}$ \\
\hline 5 & Elevation & $\begin{array}{l}\text { Areas with a high elevation are suitable for } \\
\text { watching natural landscapes and unique wild } \\
\text { plants and animal species }\end{array}$ \\
\hline 6 & Slope & $\begin{array}{l}\text { Areas with a slope of greater than } 50 \% \text { are } \\
\text { suitable for rock climbing and watching } \\
\text { natural landscapes }\end{array}$ \\
\hline 7 & Villages & $\begin{array}{l}\text { Proximately distance of 5-km away from } \\
\text { villages are great for utilities, home stays, } \\
\text { services and cultural experiences }\end{array}$ \\
\hline
\end{tabular}

\subsubsection{Data Analysis}

The key challenge to identify potential ecotourism sites was selecting suitable factors to be used in the GIS analysis. In this research, experts' opinions based local knowledge were applied asked to assign an importance of analyzed factors. During the process, we carefully attempted to assign factor priority, weight and class weight (rating) to the parameters to produce the final land suitability map of ecotourism. Thus, we assessed the areas based on three main ecotourism development aspects, including 1) potential sites for inland recreational activities, 2) potential sites for beautiful ecological sceneries, and 3) potential sites for historical and cultural experiences. Then, 4) the final step was the combination of these three aspects for multipurpose ecotourism activities.

\section{Results and Discussion}

Due to the unique landscape, rich in biodiversity and cultural values, Xaisomboun has great potential areas to can be developed for ecotourism. It consists of dense forests and high attitude mountains with unique natural, cultural, and historical sites. We identified those potential areas into three different ecotourism types of activities, as explained below. 


\subsection{Potential Sites for Inland Recreational Activities}

Potential sites for inland recreational activities are scattered in many different places, which are around $12.21 \%$ (1200 ha) of the entire area of Xaisomboun province. The Nam Ngum 1 and 2, (the largest reservoir in the province), Nam Niep river (the water basin of the hydrological power), and Nam Mang watershed are among important surface waters which can be developed for water resorts and other inland recreational activities (Figure 4). It is over 20,000 ha of watershed areas. These activities are for example sports, swimming, fishing and even family gathering activities. These areas are also located in mainly the Nam Phai and Nam Cha of the major rivers and springs. Figure 4 shows potential sites for inland recreational activities including water resorts, sports, swimming, and fishing. The top right photo shows the reservoir of the Nam Ngum Dam

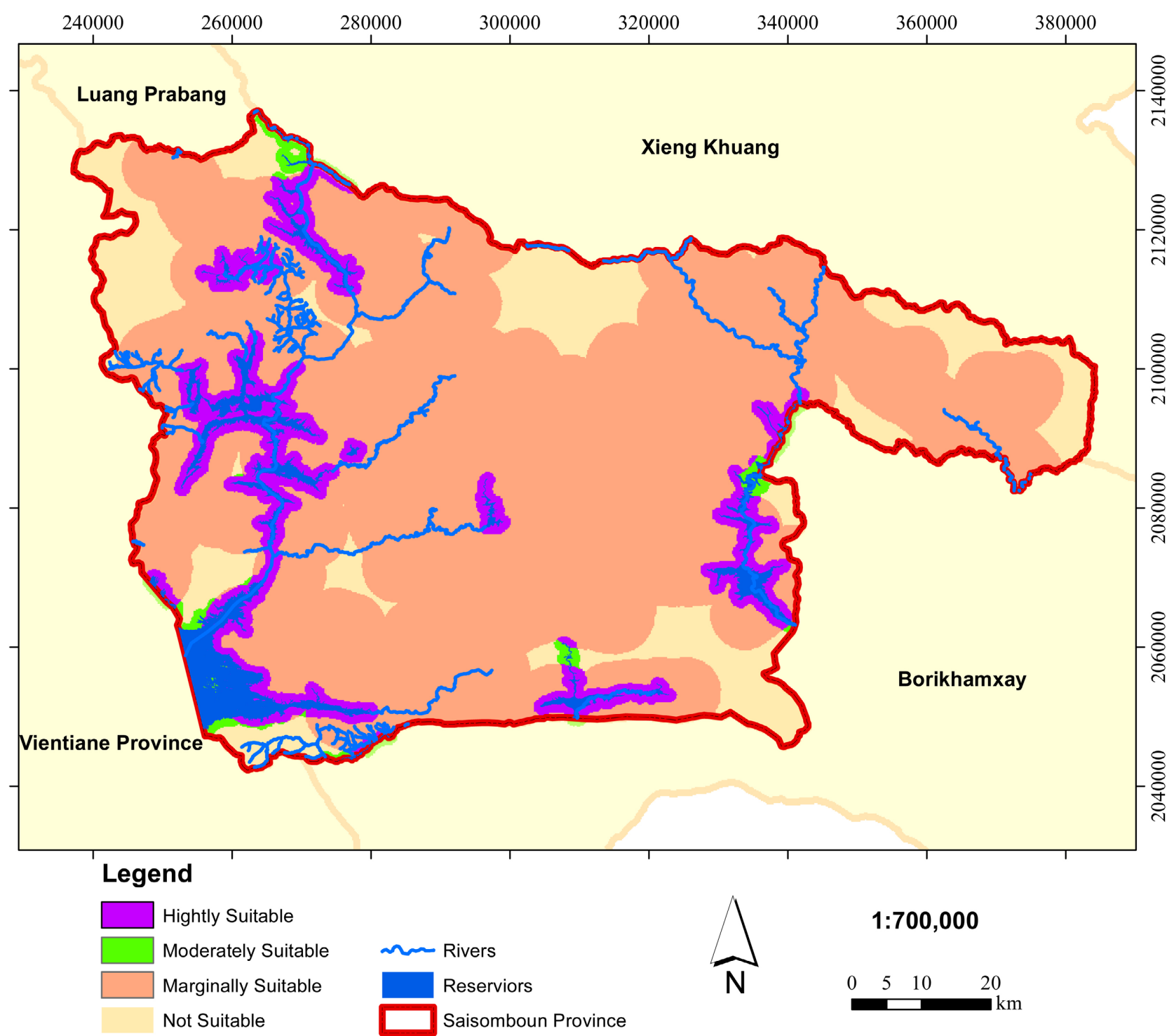

Figure 4. Potential sites for water-related recreational activities. Source: all spatial data was collected from PoNRE in Xaisomboun province. 
while the bottom photo is one of the most amazing natural aquariums of province situated at the distance of $15 \mathrm{~km}$ far from the Anouvong district. Tad Poung waterfall is located about $8 \mathrm{~km}$ from Long San village near Nam Ngum reservoir. The location has a total area of wetlands is about 10 ha. This area is considered as one of the interesting points. There are also waterfalls including Pha Chele and other waterfall.

There are several places including about $30 \mathrm{~km}$ west of Anouvang Town near Kongkhao Mountain, Tad Houay Nok Waterfall plunges 200 metres near Ban Nam Mo and Thong Hak Villages. The falls are a favourite holiday destination among locals. You can also visit nearby farms growing sugarcane and bananas. Easily accessed from Vientiane Province, Nam Ngum Lake and its river reaches into Xaysomboun Province, $35 \mathrm{~km}$ south of Anouvong Town. Located about 8 $\mathrm{km}$ from Long San Village near Nam Ngum Lake, the two-tier Tad Poung Waterfall tumbles 10 meters and then 8 meters through thick forest. About $10 \mathrm{~km}$ further along, Dan Pha Saeb Cliff launches a 30-metre-wide two-tier waterfall, each about 10 meters high. The top falls run underground, while the second can be found where giant beehives hang. In the province's northwest, Phou Mork Mountain is accessed from Long Cheng Village, and presents a great place to view the "sea clouds" from above. The Tad Pha Chae Lae Waterfall shoots 100 meters off a forested mountain about $6 \mathrm{~km}$ from Hom at Ban Nam Khien Village. Set in Xaysomboun's northeast, Tad Gnong Waterfall drops 30 meters in the Ban Pak Gnong Protected Area in Tha Thom District, about $2 \mathrm{~km}$ from Tha Thom on the Route 1D. This area is rich in biological species and rare wildlife. Near Chao Anouvong Cave is Tad Phouyathao and Tad Longsan Waterfall and Pha Hom Hot Spring known for its therapeutic waters.

\subsection{Potential Sites for Beautiful Ecological Sceneries}

The potential zone for beautiful ecological sceneries covers about $22.46 \%$ (1980 ha) of the entire study area (Figure 5). There are largely dense forests, river streams and relatively accessible by roads that mainly distributed over the entire province, excepting settlement and cropland areas. The forests are evergreen, Shorea mixed deciduous forest, dry dipterocarp and coniferous forest. The province has a part of Phou Khao Khouay National Biodiversity Conservation Area (PKK NBCA). This is a protected area located in the south covering an area of 2000 square kilometers of Xaisomboun and other connected provinces. Its mountainous topography, with elevation varying from $200 \mathrm{~m}$ to $2820 \mathrm{~m}$. Phou Bia Mountain stands as the nation's highest mountain (peaks at $2820 \mathrm{~m}$ ) located 30 $\mathrm{km}$ north of the provincial capital in Anouvang District. It is a natural habitat for various wildlife species, and a rare type of smooth, soft grass that resembles straw. The valley presents thousands of interesting Mai Long Leng trees. Sandstones with hardly any soil cover are also part of the topography of the PKK NBCA which consists of sandstone cliffs, river gorges and three large rivers with tributaries connecting to the Mekong River. There are plenty of wild animals 


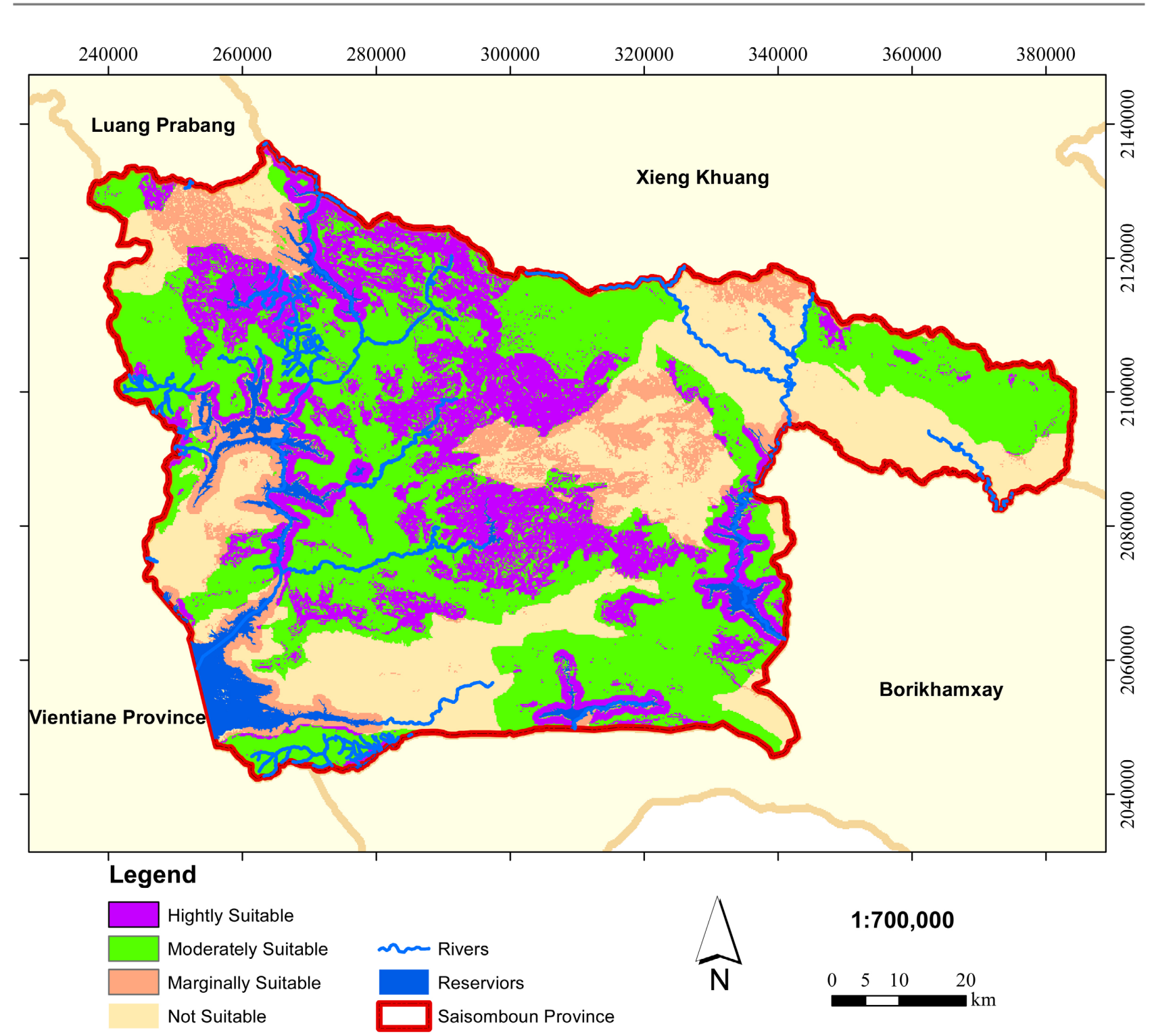

Figure 5. Potential sites for forest landscapes related activities. Source: all spatial data was collected from PoNRE in Xaisomboun province.

discovered in this landscape such as elephants, tigers, bears, 13 pairs of whitecheeked gibbons, and langurs and many species of reptiles, amphibians and birds. In Nakhay and Ban Nakhan Thoung village, there is the green peafowl population which is native to the tropical forests and nearly extinct bird species. This is recently serious preserved by local authorities. Set in Xaysomboun's northeast, Tad Gnong Waterfall drops 30 meters in the Ban Pak Gnong Protected Area in Tha Thom District, about $2 \mathrm{~km}$ from Tha Thom on the Route 1D. This area is rich in biological species and rare wildlife. These unique ecosystem values could be potentially attractive to tourists to visit the province.

\subsection{Potential Sites for Historical Tourism Activities}

Figure 6 shows the historical attractive points which are potential areas for 


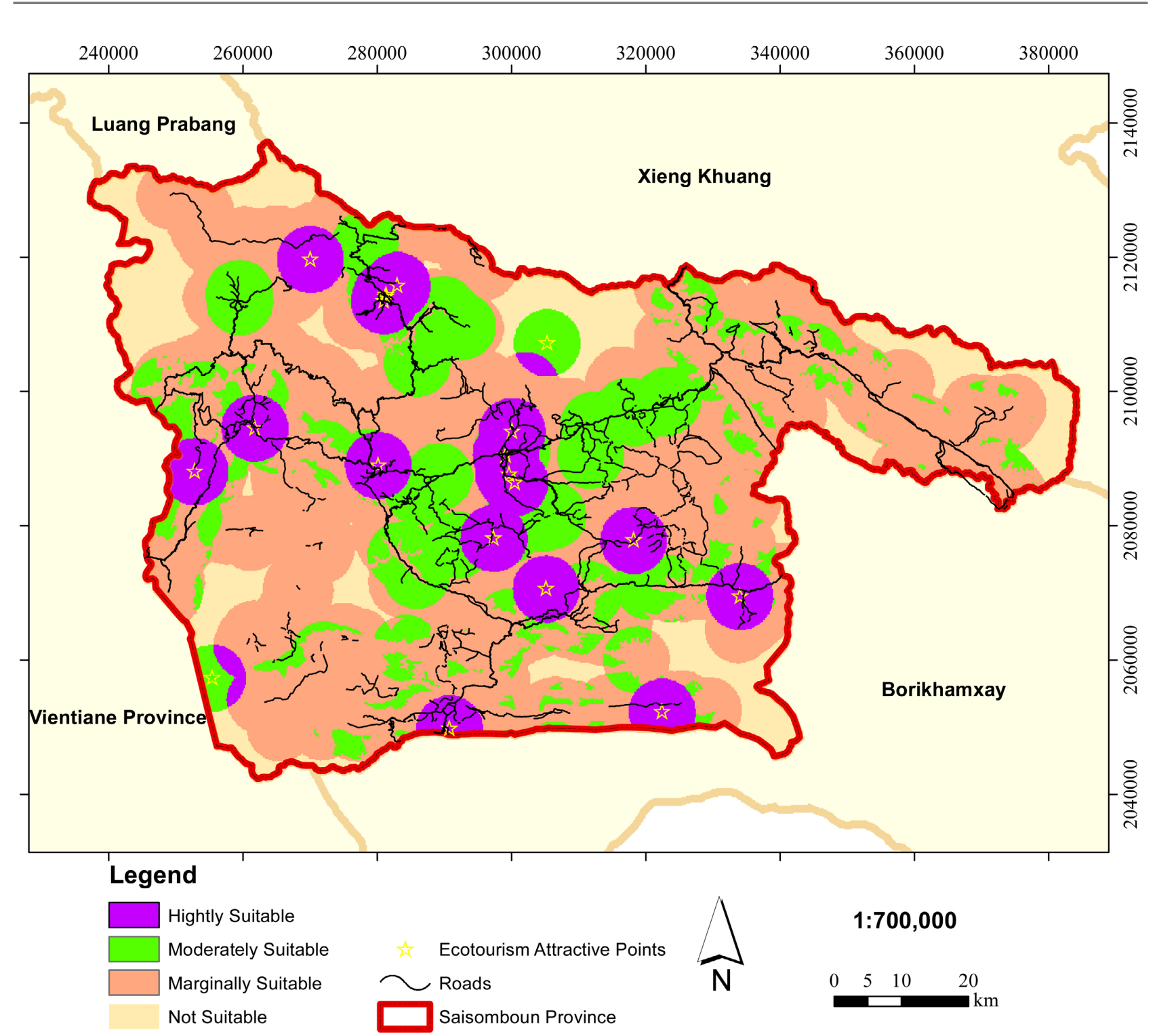

Figure 6. Potential sites for historical tourism activities. Source: all spatial data was collected from PoNRE in Xaisomboun province.

historical tourism promotion. This indicates about $12 \%$ or 1143 ha of the most suitable locations, across the province that can be promoted as historical sites integrating local community's engagement. About 1794 ha or $20.34 \%$ of entire provincial land areas are moderately suitable. History of the cave known as Chaoanouvong cave, about $4 \mathrm{~km}$ from Anouvong Town in Phouhuaxang Village, Chao Anouvong Caves are surrounded by mountains including Phou Bia, with the Nam Jang River (Nam Ja) running through the pair of caverns. The first is 7 metres high and 4 metres wide and creeps along for 30 metres. The second is 3.5 metres high and 5 metres wide, with a length of 300 metres, and is supposed to have hidden King Anouvong from the invading Siamese army. He eventually re-emerged to set up a stronghold on the Nam Jang Riverbank. Near Long Cheng Village, you'll find the $2 \times 2$-metre Khoum Molakot Battle Bunker built from 
bombshells by General Vang Pao's troops in 1969. Erected in 1967, in the province's north-western corner near Long Cheng Village, the Palace of King Sisavang Watthana was the vacation home for the royal family during the dry season. Upon achieving independence in 1975, the new government renovated the building into a museum. Nearby, General Vang Pao's House was built in 1966 during the Indochina War. The 21-room residence is open to the public during working hours, and serves as a memorial to the country's history. The old Long Cheng Airfield, used during the war, still stands nearby.

\subsection{Potential Sites for Multipurpose Ecotourism Activities}

Considering all key factors, including closed distance to forest cover and land use (protected areas), reservoir, tourism attractive points, roads, high elevation and slope and village locations, it indicated potential sites for ecotourism as shown in Figure 7, Figure 8 and Table 3. These areas can be the best site

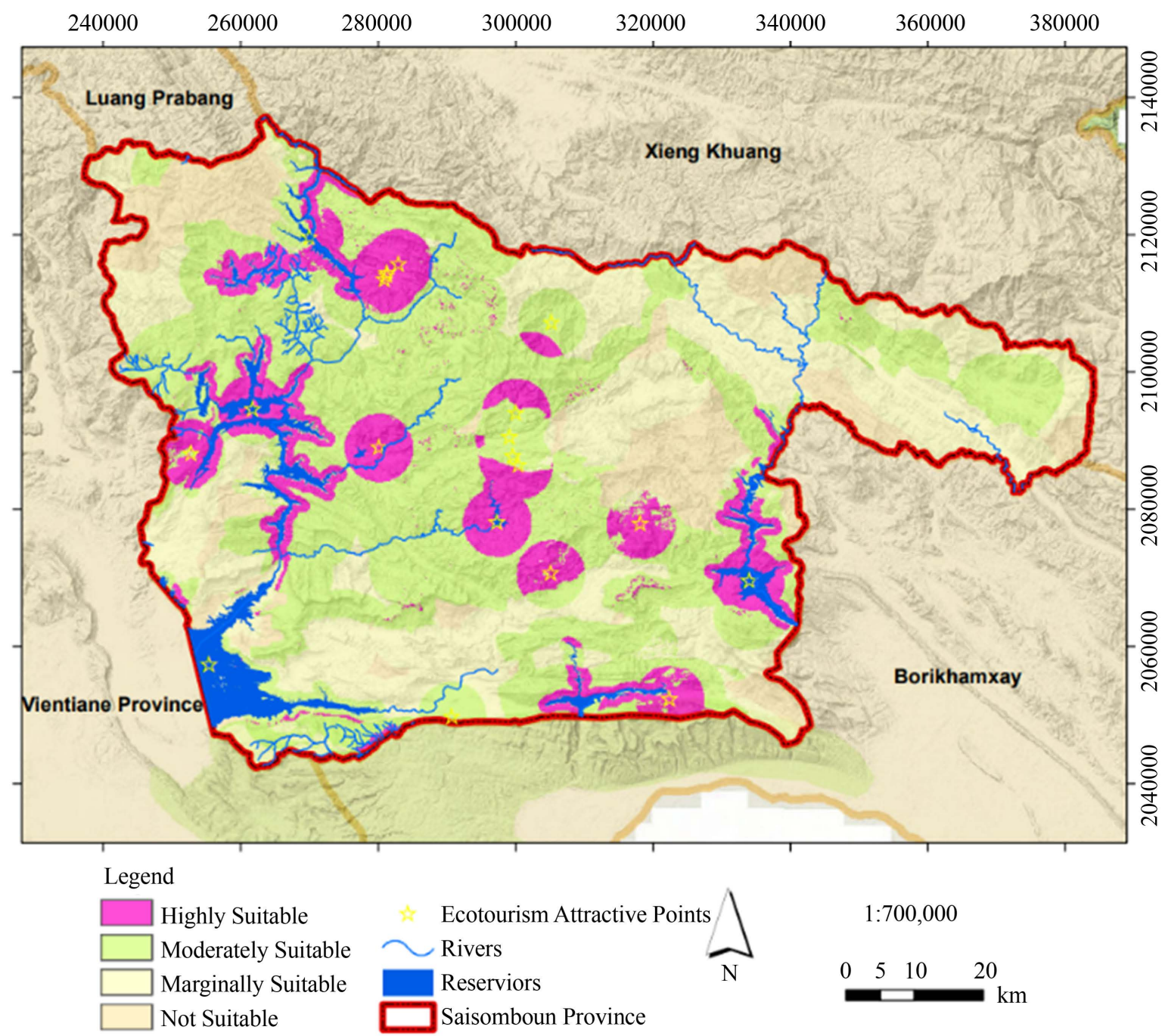

Figure 7. Potential sites for multipurpose ecotourism activities. Source: all spatial data was collected by PoNRE in Xaisomboun province. 


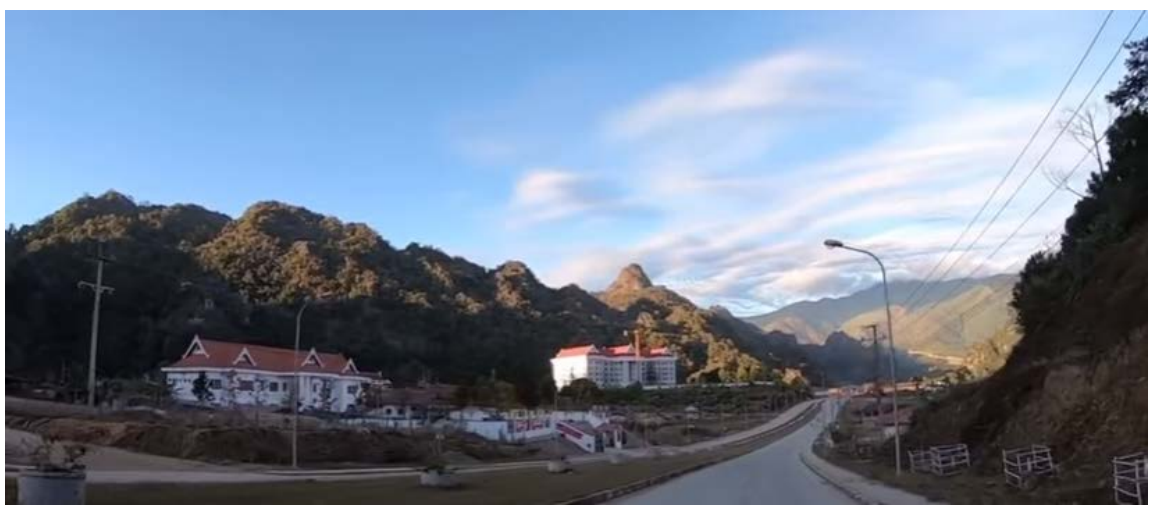

(a)

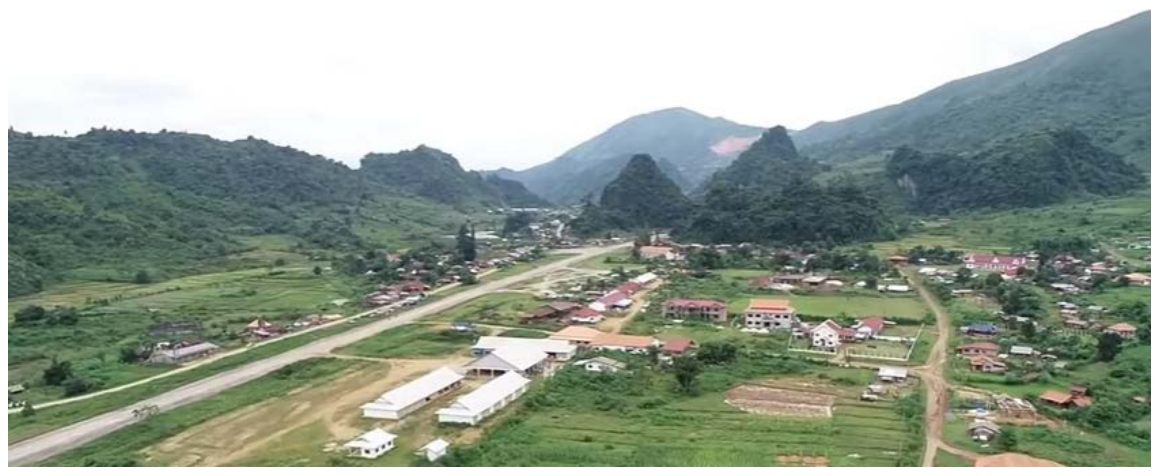

(b)

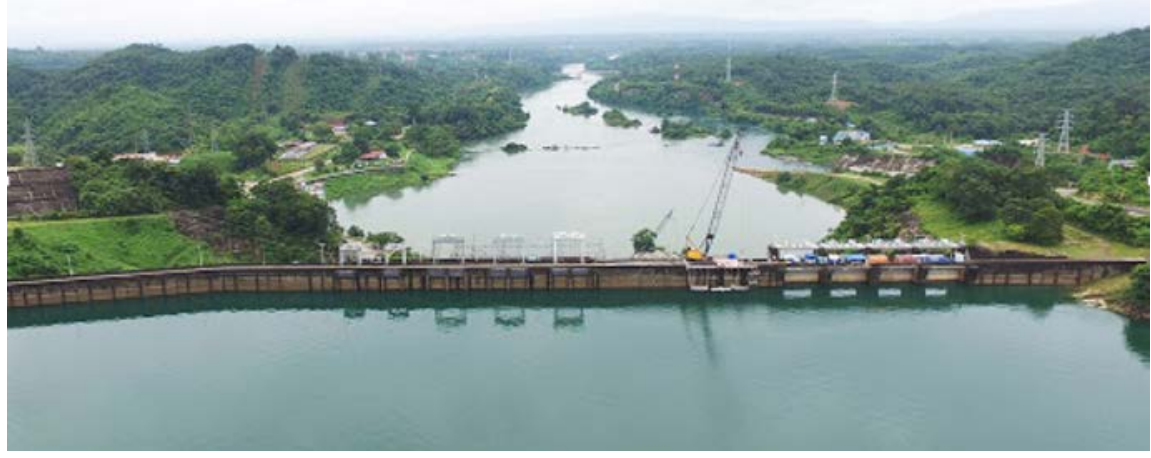

(c)

Figure 8. Some photos of Xaisomboun province, surrounding by (a) dense forests, (b) mountains and (c) hydropower. Source: Photos were provided by PoNRE technical staff.

Table 3. Potential sites for multipurpose ecotourism activities.

\begin{tabular}{ccc}
\hline Suitable Classes & Area Coverage (ha) & $\%$ \\
\hline Highly suitable & 1031 & 12.43 \\
Moderately suitable & 1612 & 19.42 \\
Marginally suitable & 4216 & 50.79 \\
Not suitable & 1441 & 17.37 \\
Total Area & $\mathbf{8 3 0 0}$ & 100 \\
\hline
\end{tabular}


possess all above mentioned qualities, which can be developed for ecotourism. These potential sites can be ideal activity at higher elevation, closer to valley and residential areas for community income support, nearby road, airport and water bodies for ensuring access to the potential sites. The results indicated about $12.43 \%$ or 1031 ha of a total area across the province, the most suitable area that can be promoted as ecotourism sites integrating local community's engagement. The analysis indicated that about $19.42 \%$ or 1612 of land areas considered as moderately suitable.

Nearly $70 \%$ is not suitable for ecotourism development. These areas are considered due to either less forest covers or not located in National/Provincial Biodiversity Conservation Areas, which are without beautiful ecotourism sceneries, far away from reservoir areas, lake and aquatic surfaces such as hydropower and rivers, more than a distance of 5-km away from tourism attractive points, such as the historic monuments, cave and interesting features, difficult to access due to more distance over $5-\mathrm{km}$ away from roads, less elevation which are not suitable for watching natural landscapes and unique wild plants and animal species, less slope that is not suitable for rock climbing and watching natural landscapes, as well as far away from villages that considering limited utilities, home stays, services and cultural experiences (Figure 7).

\section{Conclusion}

This research aimed to identify the potential sites for ecotourism in Xaisomboun province, Laos. The GIS data analysis was conducted by using seven factors describing biophysical characteristics, including forest cover, water, elevation, slope, proximity to village, road accessibility and historical attractive sites. The result suggested practically useful for the development of ecotourism sites and facilities. It was found that for the highly suitable areas (12.43\%), most of which are located in the protected areas consisting of dense forests. Its high value of natural resources is suitable for research and education. The moderately suitable area was about $19.42 \%$ of the total area that could serve as major attractions for ecotourism. Most of them are located across the provincial areas. The majority of the marginally suitable area ( $50 \%$ of the total area). Most of them can be incorporated with appropriate infrastructures and local engagement and improved services, under the supportive policy and guidelines. The result is useful for ecotourism development and planning at provincial level which can be scaled up. It is also the great benefit in terms of sustainable social-economic development, conservation of biodiversity and other ecosystem services. The study was considered as the first study which based on perspective of natural resource management and future sustainable ecotourism development using GIS. However, this information can be useful to identify priority areas for ecotourism and whether future land uses can be modified for future development within the province to ensure the sustainable natural forest resource management. Therefore, an ecotourism development plan should be incorporated into the development plans at 
district, provincial and regional levels to link resources which can complement each other. This would make it easier to redirect tourists away from tourism resources whose capacity is already exceeded. Assessments of government policies related to ecotourism and local capability or engagement were needed to conduct further research to ensure the effective ecotourism development in the region. The policies are essential in the short and medium term to support ecotourism development of the enterprises and local engagement. When ecotourism is operated, capacity building of local communities is important to facilitate and generate income from ecotourism services and jobs.

\section{Acknowledgements}

This study was one of my Ph.D. research chapters which supported by professors from Faculty of Forest Sciences, The National University of Laos, Vientiane Capital, Lao People's Democratic Republic and professors from Vietnam National University of Forestry (VNUF), Xuan Mai, Chuong My, Hanoi, Viet Nam, Kunming University Science and Technology, Kunming, China and Center for International Forestry Research (CIFOR), Situ Gede, Sindang Barang, Bogor, Indonesia. In addition, author would like to thank the anonymous reviewers for constructive comments concerning our manuscript and thank you for the regional forest observation (RFO) project (under the APFNet support) for supporting forest cover data.

\section{Author Contributions}

Research concept, GIS data collection, used methodology, manuscript writing and revising was leaded by Soneteng Buaxaiya. However, GIS data analysis and multiple criteria overlay analysis was supervised by Dr. Chittana Phompila. This work was technically supported by all mentioned co-authors. All authors have read and agreed to the published version of the manuscript.

\section{Conflicts of Interest}

No Conflicts of Interest.

\section{References}

Ahmadi, M., Asgari, S., \& Ghanavati, E. (2015). Land Capability Evaluation for Ecotourism Development in Ilam Province, a GIS Approach. Boletim de Ciências Geodésicas, 21, 107-125. https://doi.org/10.1590/S1982-21702015000100008

Çetinkaya, C., Kabak, M., Erbaş, M., \& Özceylan, E. (2018). Evaluation of Ecotourism Sites: A GIS-Based Multi-Criteria Decision Analysis. Kybernetes, 47, 1664-1686. https://doi.org/10.1108/K-10-2017-0392

Department of Forestry (2018). Lao PDR's Forest Reference Emission Level and Forest Reference Level for Redd+Results Payment under the UNFCCC. https://redd.unfccc.int/files/2018_frel_submission_laopdr.pdf

Diamantis, D. (1999). The Concept of Ecotourism: Evolution and Trends. Current Issues in Tourism, 2, 93-122. https://doi.org/10.1080/13683509908667847 
Dimitriou, C. K. (2017). From Theory to Practice of Ecotourism: Major Obstacles that Stand in the Way and Best Practices that Lead to Success. European Journal of Tourism, Hospitality and Recreation, 8, 26-37. https://doi.org/10.1515/ejthr-2017-0004

Fujita, Y., \& Phanvilay, K. (2008). Land and Forest Allocation in Lao People's Democratic Republic: Comparison of Case Studies from Community-Based Natural Resource Management Research. Society \& Natural Resources, 21, 120-133. https://doi.org/10.1080/08941920701681490

Kim, S. B., \& Alounsavath, O. (2015). Forest Policy Measures Influence on the Increase of Forest Cover in Northern Laos. Forest Science and Technology, 11, 166-171. https://doi.org/10.1080/21580103.2014.977358

Meyfroidt, P., Lambin, E. F., Erb, K. H., \& Hertel, T. W. (2013). Globalization of Land Use: Distant Drivers of Land Change and Geographic Displacement of Land Use. Current Opinion in Environmental Sustainability, 5, 438-444.

Nisa, Z. (2017). Potential Site Selection in Ecotourism Planning Using Spatial Decision Support Tool. International Journal of Human Capital in Urban Management, 2, 251-258.

Omarzadeh, D., Pourmoradian, S., Feizizadeh, B., Khallaghi, H., Sharifi, A., \& Kamran, K. V. (2021). A GIS-Based Multiple Ecotourism Sustainability Assessment of West Azerbaijan Province, Iran. Journal of Environmental Planning and Management, 1, 1-24. https://doi.org/10.1080/09640568.2021.1887827

Phompila, C., Lewis, M., Ostendorf, B., \& Clarke, K. (2017). Forest Cover Changes in Lao Tropical Forests: Physical and Socio-Economic Factors Are the Most Important Drivers. Land, 6, Article No. 23. https://doi.org/10.3390/land6020023

Schipani, S. (2011). Perceptions of the Impacts of Tourism among Rural Communities in Luang Namtha, Luang Prabang, Khammouane and Champasak, Lao PDR. Journal of Mekong Societies, 7, 39-53.

Simonekeo, S. (2015). A New Emergence of Tourism in Lao PDR for the Two Decades. Ph.D. Thesis, Rikkyo University.

Taye, B., Gebre, S. L., Gemeda, D. O., \& Getahun, K. (2019). Using Geospatial Techniques in the Selection of Potential Ecotourism Sites in Menz-geramidir District, Ethiopia. Ghana Journal of Geography, 11, 201-227.

Waswa Wanyonyi, J., Imwati, A., \& Boitt, M. (2016). GIS in Analysis of Potential Sites for Ecotourism-A Case Study of Kwale County. IOSR Journal of Environmental Science, Toxicology and Food Technology, 10, 43-49.

Yamano, T., Pradhananga, M., Schipani, S., Samson, J. N. G., Quiao, L., Leuangkhamsing, S., \& Maddawin, A. (2020). The Impact of COVID-19 on Tourism Enterprises in the Lao People's Democratic Republic: An Initial Assessment. ADB Briefs. https://doi.org/10.22617/BRF200187-2

Yongnou, X., Thongmanivong, S., Phengsopha, K., \& Vongvisouk, T. (2019). Impacts of Land Concession on Rural Livelihoods in Central Laos. International Journal of Science, Environment and Technology, 8, 735-746. 